\title{
MICROCLIMA EM DIFERENTES TIPOLOGIAS DE FLORESTA URBANA
}

\author{
MICROCLIMATE IN DIFFERENT TYPES OF URBAN FOREST
}

\author{
Angeline Martini ${ }^{1}$, Daniela Biondi², Antonio Carlos Batista ${ }^{3}$, Demóstenes Ferreira da Silva Filho ${ }^{4}$
}

\section{RESUMO}

A floresta urbana é fundamental para a qualidade de vida nas cidades devido os seus inúmeros benefícios ecológicos, estéticos e sociais. Esta pesquisa teve como objetivo analisar o benefício microclimático proporcionado por diferentes tipologias de floresta urbana existentes em Curitiba-PR. Para isso, foram selecionadas as seguintes tipologias: remanescente florestal, área verde com paisagismo e arborização de ruas. O microclima dessas áreas foi analisado por meio das variáveis temperatura $\left({ }^{\circ} \mathrm{C}\right)$ e umidade relativa $(\%)$ do ar, coletadas com registradores data logger modelo Hobo $\AA$, instalados em mini-abrigos meteorológicos, em 21 de fevereiro/2014 (verão) e 29 de julho/2014 (inverno), durante 24 horas, com início às $0 \mathrm{~h}$. Os resultados indicaram diferença microclimática entre as tipologias de floresta urbana. A temperatura média do ar no remanescente florestal foi menor do que nas demais áreas, enquanto a umidade relativa foi maior. A arborização de ruas apresentou maiores temperaturas e menores valores de umidade relativa. Conclui-se que as diferentes tipologias de floresta urbana apresentam microclimas distintos. As tipologias que possuem uma quantidade de vegetação mais expressiva tendem a apresentar menores valores de temperatura e maiores de umidade relativa, variando de intensidade conforme a estação do ano.

Palavras-chave: Benefício microclimático; Temperatura do ar; Umidade relativa do ar.

\section{ABSTRACT}

The urban forest is critical to the quality of life in cities because it plays numerous ecological, aesthetic and social benefits. This research aimed to analyze the microclimate benefit provided by different types of urban forest existing in Curitiba. For this, the following types were selected: remaining forest, green area with landscaping introduced and street trees. The microclimate of these areas was analyzed by means of temperature $\left({ }^{\circ} \mathrm{C}\right)$ and relative humidity (\%) of air, collected by data logger Hobo® model, installed in minishelters, on February 21st 2014 (summer) and July $29^{\text {th }}, 2014$ (winter) for 24 hours, starting at 12a.m. The results indicate microclimate difference among the types of urban forest. The average air temperature in the remaining forest was lower than in other areas, while the relative humidity was higher. The street trees showed higher temperatures and lower relative humidity values. It is concluded that the different types of urban forest have different microclimates. Typologies that have more vegetation expressive tend to have lower temperatures and higher relative humidity, varying in intensity depending of the season.

Keywords: Microclimate benefit; Air temperature; Relative humidity.

Recebido em 07.01.2016 e aceito em 04.02.2016

1 Engenheira Florestal. Doutoranda do Programa de Eng. Florestal da UFPR. Curitiba/PR. Email: martini.angeline@gmail.com

2 Engenheira Florestal, Dra., Professora Titular do Departamento de Ciências Florestais, UFPR, Bolsista de Produtividade em Pesquisa - CNPq, Curitiba/PR. Email: dbiondi@ufpr.br

3 Engenheiro Florestal, Dr., Professor Titular do Departamento de Ciências Florestais, UFPR, Bolsista de Produtividade em Pesquisa - CNPq, Curitiba/PR. Email: batistaufpr@ufpr.br

4 Agrônomo, Dr., Docente do programa de pós-graduação em Recursos Florestais da Universidade de São Paulo. Piracicaba, SP. E-mail: dfilho@usp.br 


\section{INTRODUÇÃO}

O clima é um fator importante, responsável pela variação das paisagens e diversidade biológica na Terra, sendo que nas cidades pode influenciar no desenvolvimento de tipologias e variações arquitetônicas, assim como em diferentes hábitos e costumes (BASSO; CORRÊA, 2014). O aumento da temperatura global reconhecido durante as últimas décadas não é apenas uma ideia simples ou abstrata, pois as temperaturas mais elevadas contribuem para ondas mais intensas de calor, secas e tempestades (HEINL et al., 2015).

Os problemas relacionados ao calor são uma questão importante em muitas áreas urbanas do mundo, principalmente porque deve reduzir a demanda de energia para aquecimento e aumentar a demanda de energia para refrigeração nos setores residenciais e comerciais (IPCC, 2015). Além disso, muitos habitantes das cidades em todo o mundo sofrem problemas de saúde e desconforto, causados pelo aumento do aquecimento das zonas urbanas, e há evidências convincentes de que esses problemas serão intensificados pela mudança climática global (BROWN et al., 2015).

Atualmente, a mudança climática global passou a colocar novos desafios e uma razão extra para otimizar o planejamento e gestão das áreas verdes urbanas (JIN; LO; BYRNE, 2015). Isto porque dentre as várias alternativas para fornecer refrigeração às cidades, a melhor opção documentada é a criação de parques urbanos e espaços verdes, que têm o potencial de fornecer ambientes termicamente confortáveis e reduzir a vulnerabilidade ao estresse térmico (BROWN et al., 2015).

As áreas verdes urbanas são componentes estratégicos importantes da cidade, pois contribuem com o ciclo hidrológico, controle de erosões, estabilização de encostas, regulação dos fluxos em canais de drenagem, oferecem áreas de sombreamento, retenção de partículas, redução do ruído, além de contribuírem para a democratização de espaços de lazer, atividades de educação ambiental e amenização térmica (LOMBARDO et al., 2012).

Quando a vegetação é bem distribuída o balanço de energia de toda a cidade pode ser modificado pela adição de mais superfícies evaporativas, mais radiação absorvida pode ser dissipada na forma de calor latente e a temperatura urbana pode ser reduzida (YU; HIEN, 2006). Assim, a presença da vegetação em áreas urbanas pode gerar um resfriamento localizado que se contrapõe ao efeito das ilhas de calor, fenômeno conhecido como "Ilhas de Frescor Urbano" (SHASHUA-BAR; PEARLMUTTER; ERELL, 2009), que são importantes para a saúde humana e sustentabilidade da cidade (CHEN et al., 2014). Portanto, pode ser possível usar os parques da cidade como uma medida para esfriar pelo menos porções de áreas urbanas, reduzindo a intensidade e magnitude dos impactos negativos das ilhas de calor (CHANG; LI, 2014). 
No planejamento urbano moderno, a relação de equilíbrio entre a natureza e a urbanização nas cidades, no que se refere aos fatores ecológicos, climáticos, sustentáveis e de bem-estar, passou a ser um aspecto universal (RASKOVIC; DECKER, 2015). Portanto, os estudos que procuram analisar a real influência das florestas urbanas no microclima são essenciais para compreender a dinâmica do clima urbano, buscando promover melhorias para a cidade (MARTINI et al., 2014). Para estas ações serem efetivamente implementadas no planejamento urbano e na criação das áreas verdes, são necessárias informações específicas e rigorosas a respeito do enfoque climatológico (CHANG; LI; CHAN, 2007).

Visando contribuir com a gestão da floresta urbana, esta pesquisa teve como objetivo analisar o microclima proporcionado por diferentes tipologias de floresta urbana existentes na cidade de Curitiba nas estações do verão e inverno.

\section{MATERIAL E MÉTODOS}

A pesquisa foi realizada na cidade de Curitiba, capital do estado do Paraná, localizada na região sul do Brasil a 934,6 m de altitude média. As coordenadas geográficas centrais da cidade são: latitude 25 25' 40" S e longitude 49 16' 23" W. Segundo a classificação de Köppen, o clima de Curitiba é do tipo Cfb, subtropical úmido, mesotérmico, sem estação seca, com verões frescos e invernos com geadas frequentes e ocasional precipitação de neve (IPPUC, 2011). O verão é ameno (com temperaturas médias de $19,7^{\circ} \mathrm{C}$ ) e o inverno moderado (13,4 ํㅡ em média) com alguns dias mais rigorosos. A precipitação média anual é de 1.419,91 mm com um período de estiagem, não fixo, entre o outono e o inverno (IPPUC, 2011).

Para a realização desta pesquisa, de caráter exploratório, foram selecionadas as tipologias de florestas urbanas mais frequentes nas cidades brasileiras, tais como: remanescente florestal, área verde com paisagismo e arborização de ruas. A seleção das áreas na cidade teve como critério, a proximidade entre elas (distância inferior a $2 \mathrm{~km}$ ). Assim, as áreas selecionadas para a avaliação do microclima foram: remanescente florestal Capão do Tigre/UFPR, Jardinete Henrique Knopholz e arborização da Rua Ângelo Lopes (Figura 1). 


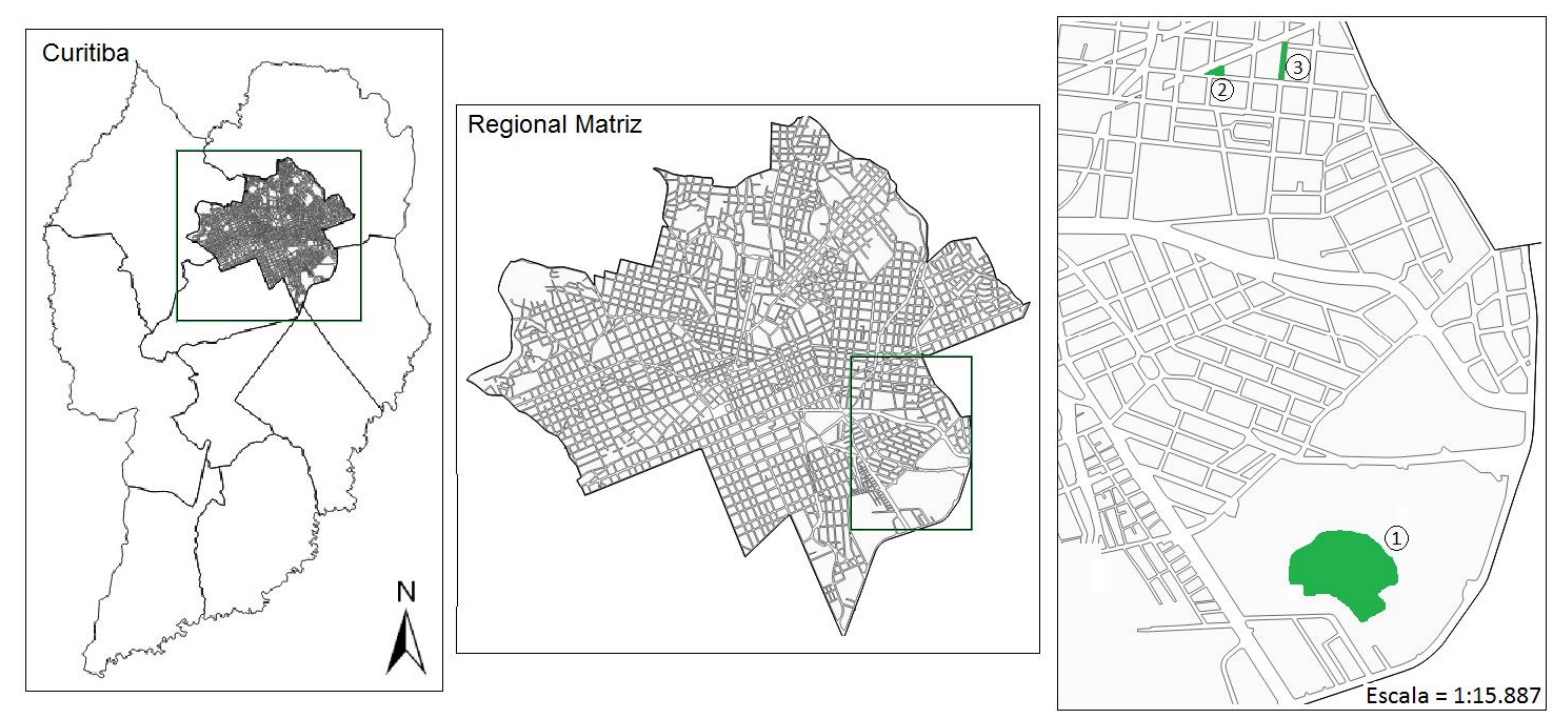

Figura 1. Localização das áreas de estudo: 1) Capão do Tigre/UFPR; 2) Jardinete Henrique Knopholz; 3) Arborização da Rua Ângelo Lopes

Figure 1. Location of the study areas: 1) Capão do Tigre/UFPR; 2) Jardinete Henrique Knopholz; 3) Afforestation of Angelo Lopes Street

O Capão do Tigre é um remanescente de Floresta Ombrófila Mista de aproximadamente 15,4 ha, localizado no bairro Jardim Botânico, no Campus da Universidade Federal do Paraná (UFPR). O Jardinete Henrique Knopholz, localizado no bairro Cristo Rei, é uma área verde com paisagismo introduzido de aproximadamente $1500 \mathrm{~m}^{2}$, formada por gramado e indivíduos arbóreos (24 exemplares), em sua maioria de grande porte: Anadenanthera colubrina (Vell.) Brenan (monjoleiro); Ceiba speciosa (A.St.-Hil.) Ravenna (paineira); e Tipuana tipu (Benth.) Kuntze (tipuana). A rua Ângelo Lopes, também localizada no bairro Cristo Rei, apresenta $2,7 \mathrm{~km}$ de extensão no sentido Norte-Sul, é arborizada principalmente por Handroanthus albus (Cham.) Mattos (ipê-amarelo) de médio porte, com 36 indivíduos por quadra, em ambos os lados da rua. Em ambos os lados da rua, a calçada apresenta passeio de $1,30 \mathrm{~m}$ e duas faixas de gramado, uma próxima ao meio fio $(0,50 \mathrm{~cm}) \mathrm{e}$ outra próxima ao muro das residências (3,0 m) (Figura 2).
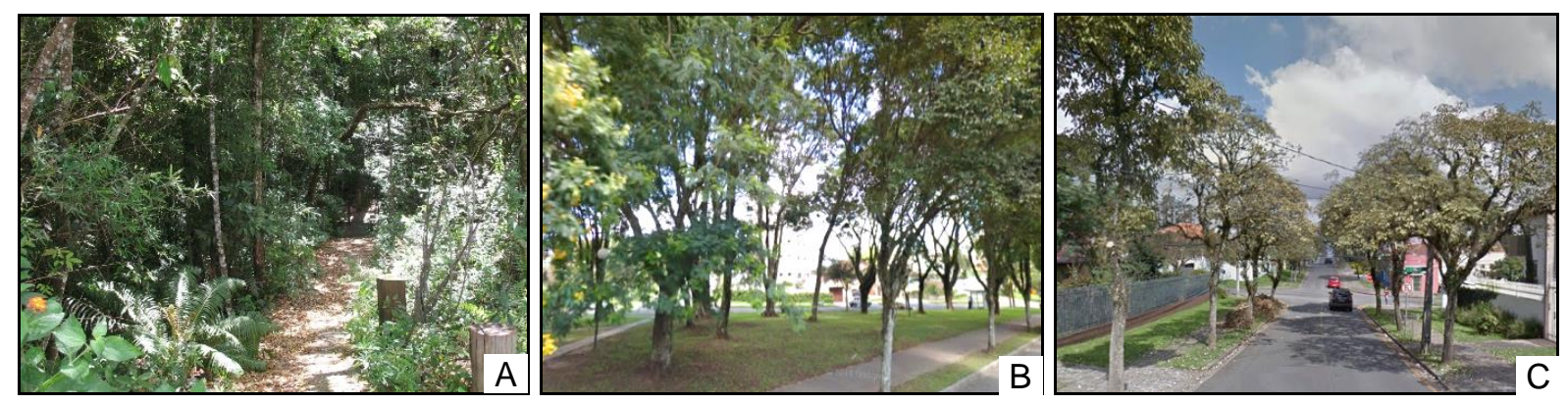

Figura 2. Áreas selecionadas na cidade de Curitiba: A) Capão do Tigre/UFPR; B) Jardinete Henrique Knopholz; C) Arborização da Rua Ângelo Lopes

Figure 2. Selected areas in Curitiba: A) Capão do Tigre/UFPR; B) Jardinete Henrique Knopholz; C) Afforestation of Angelo Lopes Street 
O microclima dessas áreas foi analisado por meio das variáveis meteorológicas temperatura $\left({ }^{\circ} \mathrm{C}\right)$ e umidade relativa do ar (\%). Estas variáveis foram coletadas com registradores data logger modelo $\mathrm{Hobo} \AA \mathrm{RH} \&$ Temp., da marca Onset, que se destinam a medir temperaturas entre - 20 e $70^{\circ} \mathrm{C}$ e umidade relativa entre 25 e $95 \%$. Estes equipamentos foram previamente aferidos e programados para armazenarem dados a cada minuto. Por questões de segurança, os registradores $\mathrm{Hobo}^{\circledR}$ foram instalados no centro de cada área de interesse (tipologias), em mini abrigos meteorológicos a $4 \mathrm{~m}$ do solo. Os abrigos foram confeccionados com uma seção de tubo PVC de $150 \mathrm{~mm}$ de comprimento e $100 \mathrm{~mm}$ de diâmetro, com aberturas nas laterais e revestidos externamente com papel alumínio, fechados por duas tampas. Foram fixados no tronco das árvores na posição vertical, com auxílio de uma fita abraçadeira de nylon (Figura 3).

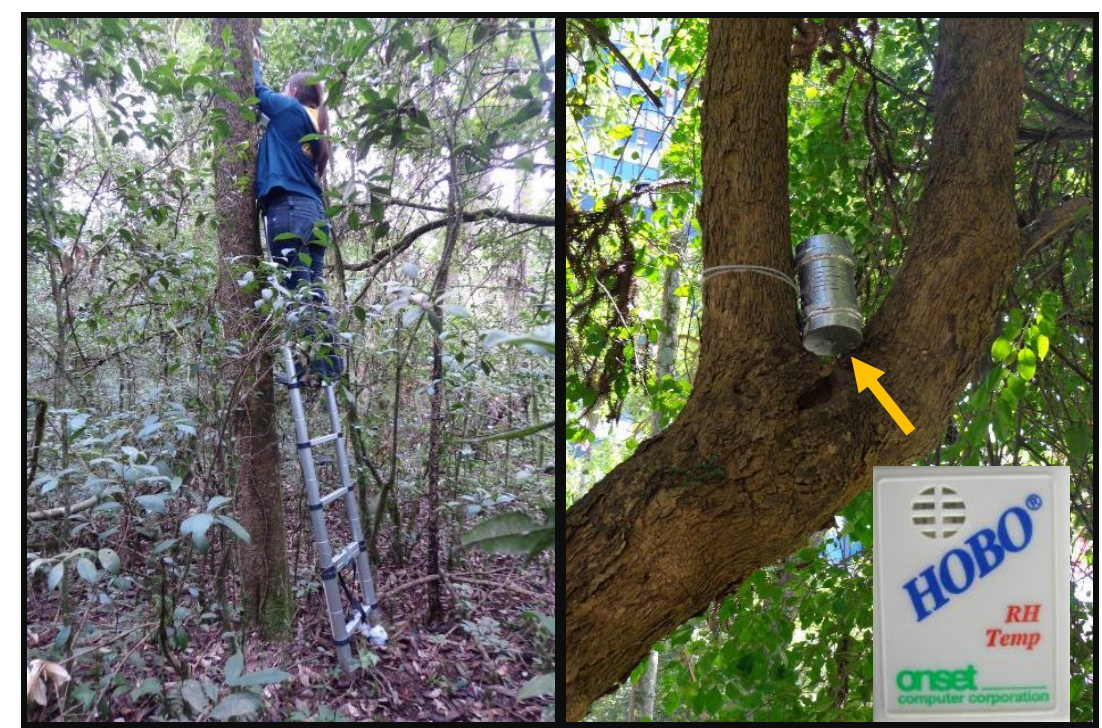

Figura 3. Instalação do mini-abrigo meteorológico na árvore (à esquerda) e detalhe do mini-abrigo e equipamento utilizado - data logger Hobo® RH \& Temp (à direita)

Figure 3. Installation of meteorological mini-shelter in the tree (left) and the detail of mini-shelter and used equipment - data logger Hobo® RH \& Temp (right)

A coleta de dados foi realizada nos dias 21 de fevereiro de 2014 (verão) e 29 de julho de 2014 (inverno) durante 24 horas, com início às 0h, totalizando 1441 leituras. Os dias foram caracterizados como de céu limpo e sem previsão de chuva. A pesquisa foi realizada nestas duas estações do ano, para identificar o microclima proporcionado pelas tipologias de floresta urbana em situações extremas de calor e frio na cidade, uma vez que primavera e outono, não apresentam características climáticas tão distintas.

Após o período da coleta, os dados foram descarregados no computador e transferidos para o programa Excel, onde foram processados. As médias foram calculadas separadamente para cada estação do ano a partir do total de dados coletados em cada tipologia de floresta urbana, sendo testadas estatisticamente pelo teste $\mathrm{F}$ e comparadas pelo 
teste SNK a 1\% de significância. Para cada tipologia de floresta urbana foram determinadas a temperatura máxima, mínima e a amplitude térmica (variação entre maior e menor temperatura). Além disso, determinou-se a média de temperatura e umidade relativa para cada hora, o que possibilitou a elaboração de gráficos representativos da variação de temperatura e umidade relativa do ar.

\section{RESULTADOS E DISCUSSÃO}

O microclima proporcionado pela vegetação é influenciado diretamente por suas características e composição, expostas aqui como tipologia de floresta urbana, sendo que os resultados indicaram diferença estatística significativa entre o microclima das diferentes tipologias de floresta urbana analisadas (Tabela 1).

Tabela 1. Valores médios das variáveis temperatura (Temp) e umidade relativa do ar (UR) nas tipologias de floresta urbana, com resultado do teste SNK (1\%)

Table 1. Average values of the variables temperature (Temp) and relative humidity (UR) in the typologies of urban forest, with a result of SNK test (1\%)

\begin{tabular}{ccccc}
\hline & \multicolumn{2}{c}{ Verão } & \multicolumn{2}{c}{ Inverno } \\
\hline Tipologia de Floresta Urbana & Temp $\left({ }^{\circ} \mathbf{C}\right)$ & UR $(\%)$ & Temp $\left({ }^{\circ} \mathbf{C}\right)$ & UR (\%) \\
\hline Remanescente florestal & $20,9 \mathrm{a}$ & $89,7 \mathrm{a}$ & $12,7 \mathrm{a}$ & $97,4 \mathrm{a}$ \\
Área verde com paisagismo & $23,1 \mathrm{~b}$ & $68,9 \mathrm{c}$ & $13,3 \mathrm{~b}$ & $86,3 \mathrm{C}$ \\
Arborização de ruas & $23,7 \mathrm{C}$ & $70,5 \mathrm{~b}$ & $13,5 \mathrm{C}$ & $87,1 \mathrm{~b}$ \\
\hline Nota: Médias seguidas pela mesma letra na coluna não diferem entre si pelo teste SNK a 1\%.
\end{tabular}

A temperatura no remanescente florestal foi menor do que nas demais áreas, enquanto que a umidade relativa foi maior. Já a arborização de ruas apresentou maiores temperaturas e menores valores de umidade relativa do que as demais tipologias. Resultado este que concorda com a afirmação de Mahmoud (2011). Segundo o autor, árvores isoladas, distribuídas com amplo espaçamento, como é o caso típico de uma rua urbana, não tem um efeito significativo no resfriamento.

No verão, a diferença de temperatura média entre o remanescente florestal e a área verde com paisagismo foi de $2,2{ }^{\circ} \mathrm{C}$ e entre o remanescente florestal e a arborização de ruas foi de $2,8^{\circ} \mathrm{C}$. Com relação à umidade relativa, a diferença entre o remanescente florestal e a área verde com paisagismo foi de 20,8 unidades, e entre o remanescente florestal e a arborização de ruas foi de 19,2 unidades.

No inverno, a diferença de temperatura média entre o remanescente florestal e a área verde com paisagismo introduzido foi de $0,6^{\circ} \mathrm{C}$, e entre o remanescente e a arborização de ruas foi de $0,8^{\circ} \mathrm{C}$. Para a umidade relativa, a diferença entre o remanescente florestal e a área 
verde com paisagismo foi de 11,1 unidades, e entre o remanescente florestal e a arborização de ruas foi de 10,3 unidades.

De modo geral, os valores de temperatura foram menores e os de umidade relativa maiores em áreas onde há maior número de indivíduos arbóreos, assim como em locais com árvores de grande porte ou de copa densa. Essa diminuição da temperatura ocorre porque as árvores interceptam a radiação solar e sombreiam as superfícies (ADAMS; SMITH, 2014). Como as folhas das árvores possuem baixo índice de reflexão, absorvem a radiação solar incidente e bloqueiam boa parte da radiação solar direta (BASSO; CORRÊA, 2014). Dessa forma, dependendo da densidade da folhagem, extensão e espessura da copa, elas podem interceptar grandes quantidades de radiação solar (BARBIRATO, TORRES; SOUZA, 2011). Além disso, segundo Chen et al. (2014), as árvores transformam uma pequena parte da radiação solar absorvida pela fotossíntese em calor latente (evapotranspiração), evitando que seja convertida em energia térmica.

Ao analisar os valores máximos e mínimos de temperatura, foi possível verificar também que a amplitude térmica no remanescente florestal foi menor do que nas demais áreas (Tabela 2).

Tabela 2. Valores extremos (máximos e mínimos) de temperatura $\left({ }^{\circ} \mathrm{C}\right)$ e amplitude térmica nas tipologias de floresta urbana

Table 2. Extreme values (maximum and minimum) of temperature and thermal ampleness in types of urban forest

\begin{tabular}{cccccccc}
\hline \multirow{2}{*}{ Tipologia de Floresta Urbana } & \multicolumn{3}{c}{ Verão } & & \multicolumn{3}{c}{ Inverno } \\
\cline { 2 - 4 } \cline { 6 - 8 } & mín. & máx. & $\boldsymbol{\Delta}$ & & mín. & máx. & $\Delta$ \\
\hline Remanescente florestal & 17,5 & 26,0 & 8,5 & & 11,0 & 15,2 & 4,2 \\
Área verde com paisagismo & 18,7 & 30,0 & 11,3 & & 11,8 & 16,0 & 4,2 \\
Arborização de ruas & 18,7 & 31,2 & 12,5 & & 11,4 & 17,5 & 6,1 \\
\hline Nota: $\Delta=$ variação & & & & & &
\end{tabular}

Pode-se observar na Tabela 2 que a temperatura máxima foi menor no remanescente florestal e maior na arborização de ruas, tanto no verão como no inverno. $\mathrm{Na}$ área verde com paisagismo e na arborização de ruas foi encontrado o mesmo valor de temperatura mínima no verão $\left(18,7^{\circ} \mathrm{C}\right)$, e a máxima variou apenas $1,2^{\circ} \mathrm{C}$, sendo mais alta na arborização de ruas. No inverno, a diferença entre os valores de temperatura mínima em cada ambiente foi pouco significativa, variando $0,8^{\circ} \mathrm{C}$ entre o remanescente florestal (menor valor) e a área verde com paisagismo (maior valor).

No inverno, a amplitude térmica foi menor em todas as áreas, apresentando o mesmo valor no remanescente florestal e na área verde com paisagismo $\left(4,2^{\circ} \mathrm{C}\right)$. Contudo, pode-se afirmar que a amplitude térmica tende a ser menor quando há maior quantidade de vegetação. 
Conforme afirma Velasco (2007), a amplitude térmica é inversamente proporcional à porcentagem de vegetação presente na área.

A variação da temperatura e da umidade relativa, no verão e inverno, em cada tipologia de floresta urbana indicou semelhança entre as áreas, embora tenham apresentado valores distintos, o comportamento foi sempre o mesmo (Figura 4).

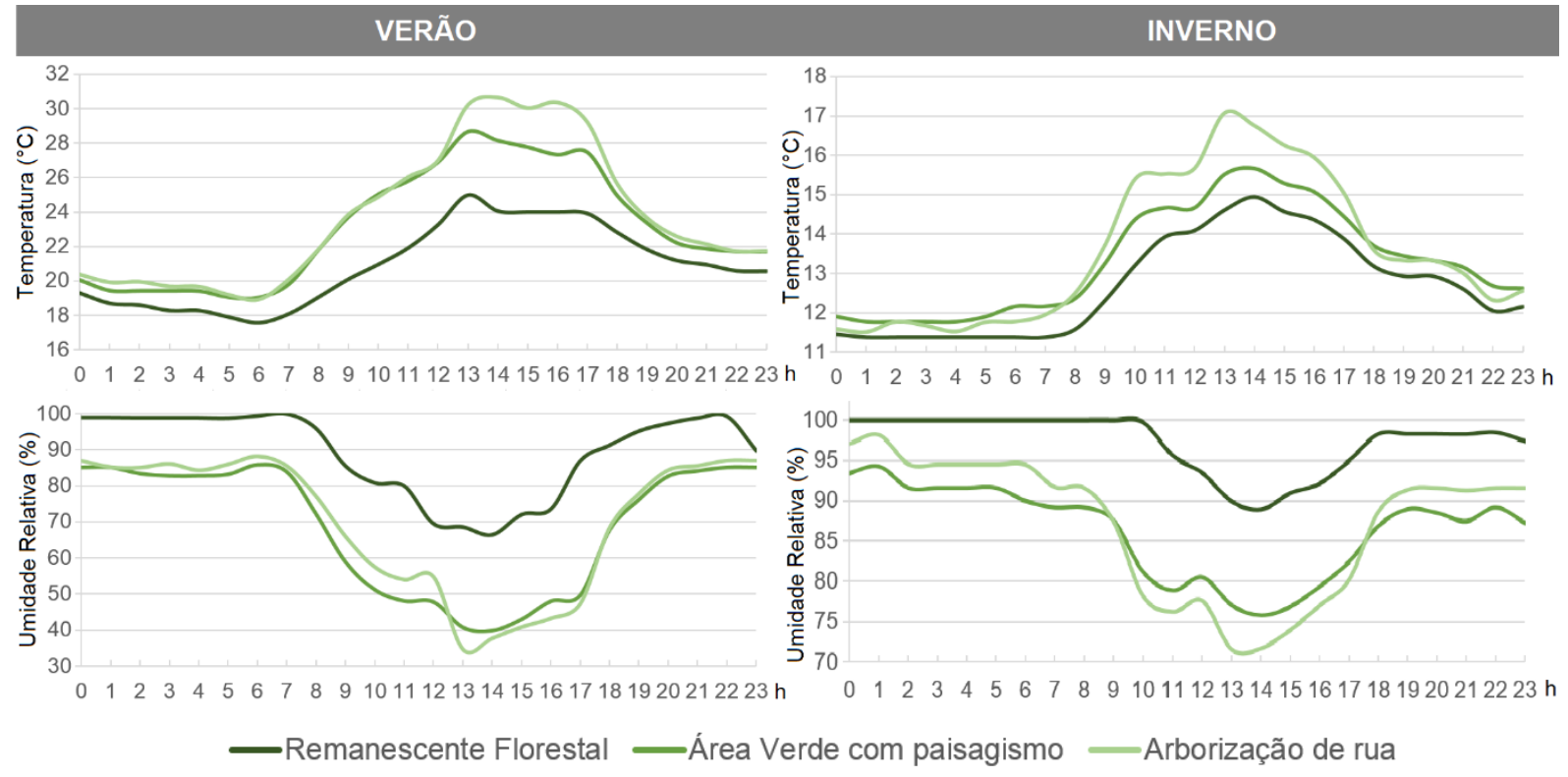

Figura 4. Variação de temperatura e umidade relativa do ar das tipologias de floresta urbana ao longo do período de coleta de dados

Figure 4. Temperature range and relative humidity of typologies of urban forest throughout the data collection period

No inverno, a menor temperatura registrada em cada tipologia de floresta urbana, variou entre as $4 \mathrm{~h}$ e $7 \mathrm{~h}$ da manhã. A maior temperatura registrada no remanescente florestal e na área verde com paisagismo ocorreu às $14 \mathrm{~h}$, enquanto que na rua arborizada este registro se deu às $13 \mathrm{~h}$, uma hora antes das demais. A umidade relativa seguiu tendência inversa para todos os quesitos. Durante a noite a diferença entre o remanescente florestal e a área verde com paisagismo foi em média $0,5^{\circ} \mathrm{C}$, e durante o dia a diferença média foi de $0,7^{\circ} \mathrm{C}$. Já a diferença entre o remanescente florestal e a arborização de ruas durante a noite foi em média $0,3^{\circ} \mathrm{C}$, enquanto que durante o dia foi de $1,5^{\circ} \mathrm{C}$.

Pode-se afirmar, que nas duas estações do ano a diferença de temperatura e umidade relativa do ar entre as tipologias de floresta urbana foram menos expressivas ao longo da noite, principalmente para a variável temperatura.

A variação da temperatura e da umidade relativa do ar nas tipologias de floresta urbana apresentou tendência semelhante em todas as áreas. Durante todo o período as temperaturas observadas no remanescente florestal (com maior área, maior densidade de copa e maior número de indivíduos) foram menores do que nos demais ambientes, contrariando o 
exposto por Velasco (2007). Em seu estudo realizado na cidade de São Paulo, constatou-se que às $7 \mathrm{~h}$ da manhã, durante o mês de setembro, a área com maior quantidade de vegetação apresentou maiores temperaturas do que as áreas com menos vegetação e justificou tal fato pela capacidade que a vegetação tem em reter o comprimento de onda longa emitida pelas superfícies, o que faz com que o calor demore mais tempo para se dissipar (VELASCO, 2007). Sendo assim, na presente pesquisa, a capacidade da vegetação em reter o calor não foi mais expressiva do que a capacidade de "refrescar" o ambiente.

Com relação às estações do ano, foi possível observar que o comportamento das variáveis meteorológicas foi semelhante em todas as tipologias de floresta urbana. $\mathrm{O}$ que variou foi a intensidade dos valores, sendo a diferença de temperatura entre os ambientes mais expressiva no verão e menos acentuada no inverno. Para a variável umidade relativa, observou-se o contrário, variação mais acentuada entre os ambientes no inverno. Ambos os resultados também foram encontrados nos estudos de Velasco (2007). Segundo Chang, Li e Chan (2007), no verão, a temperatura das áreas com vegetação tem efeito mais forte de resfriamento do que no inverno e na pesquisa realizada por Dacanal, Labaki e Silva (2010), foi observada maior diferença de umidade relativa do ar no inverno.

A comparação das tipologias de floresta urbana quanto aos benefícios que podem promover ainda é um assunto pouco estudado, provavelmente devido às dificuldades de se comparar ambientes com características distintas. O benefício microclimático é diretamente influenciado pelo tipo de vegetação, características da espécie, como porte e densidade de copa, bem como, número de indivíduos, área do terreno, dentre outros fatores. Portanto, quando se analisa o microclima das tipologias de floresta urbana, estão sendo estudadas as variáveis meteorológicas resultantes da influência de certos agrupamentos estabelecidos que foram representados pelas diversas configurações que a vegetação apresenta na paisagem urbana. Embora apresente algumas ressalvas, a análise do microclima das tipologias de floresta urbana pode ser um excelente método de abordagem, conforme foi possível observar nesta pesquisa.

\section{CONCLUSÕES}

As diferentes tipologias de floresta urbana (remanescente florestal, área verde com paisagismo e arborização de ruas) apresentam microclima distintos. As tipologias que possuem quantidade de vegetação mais expressiva apresentaram menores valores de temperatura e maiores de umidade relativa. A diferença entre essas áreas varia conforme a estação do ano, sendo mais acentuada no verão, principalmente para a variável temperatura. 
O remanescente florestal foi o que apresentou menores valores de temperatura e maiores valores de umidade relativa do ar, enquanto que a arborização de ruas foi a tipologia que apresentou maiores valores de temperatura e menores valores de umidade relativa. Contudo, a variação microclimática das tipologias de floresta urbana, ao longo do período de estudo, seguiu a mesma tendência nas duas estações do ano, apresentando comportamento semelhante em todas as áreas. Além disso, destaca-se que no período noturno as diferenças microclimáticas entre as tipologias de floresta urbana são menos expressivas, principalmente para a variável temperatura do ar.

\section{AGRADECIMENTOS}

À Fundação Araucária de Apoio ao Desenvolvimento Científico e Tecnológico do Paraná pelo financiamento à compra dos equipamentos.

\section{REFERÊNCIAS}

ADAMS, M. P.; SMITH, P. L. A systematic approach to model the influence of the type and density of vegetation cover on urban heat using remote sensing. Landscape and Urban Planning, Amsterdã, v. 132, p. 47 - 54, 2014.

BARBIRATO, G. M.; TORRES, S. C.; SOUZA, L. C. L. de. Clima Urbano e eficiência energética nas edificações. Rio de Janeiro: Programa Nacional de Eficiência Energética em Edificações (PROCEL EDIFICA), 2011.

BASSO, J. M.; CORRÊA, R. S. Arborização urbana e qualificação da paisagem. Paisagem e Ambiente, São Paulo, n. 34, p. 129 - 148, 2014.

BROWN, R. D.; VANOS, J.; KENNY, N.; LENZHOLZER, S. Designing urban parks that ameliorate the effects of climate change. Landscape and Urban Planning, Amsterdã, v. 138, p. $118-131,2015$.

CHANG, C.; LI, M.; CHANG, S. A preliminary study on the local cool-island intensity of Taipei city parks. Landscape and Urban Planning, Amsterdã, v. 80, p. 386 - 395, 2007.

CHANG, C.; LI, M. Effects of urban parks on the local urban thermal environment. Urban Forestry \& Urban Greening, Amsterdã, v. 13, p. 672 - 681, 2014.

CHEN, A.; YAO, X. A.; SUN, R.; CHEN, L. Effect of urban green patterns on surface urban cool islands and its seasonal variations. Urban Forestry \& Urban Greening, Amsterdã, v. 13, p. $646-654,2014$.

DACANAL, C.; LABAKI, L. C.; SILVA, T. M. L. Vamos passear na floresta! O conforto térmico em fragmentos florestais urbanos. Ambiente Construído, Porto Alegre, v. 10, n. 2, p. 115 132, 2010. 
HEINL, M.; HAMMERLE, A.; TAPPEINER, U.; LEITINGER, G. Determinants of urban-rural land surface temperature differences - A landscape scale perspective. Landscape and Urban Planning, Amsterdã, v. 134, p. 33 - 42, 2015.

INSTITUTO DE PESQUISA E PLANEJAMENTO URBANO DE CURITIBA (IPPUC). Desenvolvimento sustentável: Indicadores de sustentabilidade de Curitiba - 2010. Curitiba: IPPUC, 2011. 77p.

INTERGOVERNMENTAL PANEL ON CLIMATE CHANGE (IPCC). Mudança do Clima 2014 Impactos, Adaptação e Vulnerabilidade: sumário para tomadores de decisão. Tradução de: Iniciativa Verde. São Paulo: Iniciativa Verde, 2015. Climate Change 2014 - Impacts, Adaptation, and Vulnerability: Summary for Policymakers.

JIM, C.Y.; LO, A. Y.; BYRNE, J. A. Charting the green and climate-adaptive city. Landscape and Urban Planning, Amsterdã, v. 138, p. 51 - 53, 2015.

LOMBARDO, M. A.; SILVA FILHO, D. F; FRUEHAUF, A. L.; PAVAN, D. C. O uso de geotecnologias na análise de da ilha de calor, índice de vegetação e uso da terra. Revista Geonorte, Manaus, v. 2, n. 5, p. 520 - 529, 2012.

MAHMOUD, A. H. A. Analysis of the microclimatic and human comfort conditions in an urban park in hot and arid regions. Building and Environment, Amsterdã, v. 46, p. 2641 - 2656, 2011.

MARTINI, A.; BIONDI, D.; BATISTA, A. C.; SILVA FILHO, D. F. da. Validação da metodologia de transectos móveis para coleta de dados microclimáticos no ambiente urbano. In: SIMPÓSIO BRASILEIRO DE CLIMATOLOGIA GEOGRÁFICA, 11., 2014, Curitiba/PR. Anais... Curitiba: ABCLIMA, 2014.

RASKOVIC, S.; DECKER, R. The influence of trees on the perception of urban squares. Urban Forestry \& Urban Greening, Amsterdã, v. 14, p. 237 - 245, 2015.

SHASHUA-BAR, L.; PEARLMUTTER, D.; ERELL, E. The cooling efficiency of urban landscape strategies in a hot dry climate. Landscape and Urban Planning, Amsterdã, v. 92, p. 179 - 186, 2009.

VELASCO, G. D. N. Potencial da arborização viária na redução do consumo de energia elétrica: definição de três áreas na cidade de São Paulo - SP, aplicação de questionários, levantamento de fatores ambientais e estimativa de Graus-Hora de calor. 123f. Tese (Doutorado em Agronomia) - Escola Superior de Agricultura Luiz de Queiroz, Universidade de São Paulo, Piracicaba, 2007.

YU, C.; HIEN, W. N. Thermal benefits of city parks. Energy and Buildings, Amsterdã, v. 38, p. $105-120,2006$. 